\title{
The effect of sympathomimetic drugs on contractility of the vas deferens in vitro and in vivo*
}

\author{
W. D. Ratnasooriya $\dagger$, R. M. Wadsworth and D. P. Gilmoreł \\ Department of Physiology and Pharmacology, University of Strathclyde, Glasgow G1 1XW, \\ and $\ddagger$ Institute of Physiology, Glasgow University, Glasgow G12 8QQ, U.K.
}

\begin{abstract}
Summary. The sympathomimetic drugs noradrenaline, methoxamine, tyramine and norephedrine caused rhythmic contractions in isolated human vasa deferentia. Provided the drug was not washed out, these contractions lasted for the entire duration of the experiment $(4-6 \mathrm{~h})$. These contractions were mediated via $\alpha$ adrenoreceptors. Intravenous administration of methoxamine or oxymetazolene to rats or guinea-pigs produced contractions of the vas deferens in vivo in some experiments but was accompanied by severe cardiovascular side effects. A local method of application was developed, using mixtures of tyramine with Silastic prepared as collars specially designed to fit round the vas deferens. Acute and chronic insertion of these slow-releasing devices around the vas deferens of rats produced rhythmic contractions of the vas deferens without any serious side effects.
\end{abstract}

\section{Introduction}

Several possible methods for contraception in the male have been investigated (for reviews see de Kretser, 1976; Patanelli, 1975). As yet, however, no safe, reliable and reversible male contraceptive has been discovered. Drugs which interfere with spermatogenesis also frequently inhibit libido, are not rapidly active or rapidly reversible, and the danger of chromosomal damage may also exist (Patanelli, 1975). Surgical methods such as vasectomy or occlusion of the vas deferens suffer from the serious disadvantage that they are difficult to reverse (Lubell \& Frischer, 1976). On the other hand, if an antifertility effect could be produced by a drug exerting its action on the ductular system then most of the disadvantages encountered with other methods would probably be overcome. One way of achieving such a goal is to alter sperm transit rate in the epididymis or vas deferens by producing repeated rhythmic contractions in the vas deferens smooth muscle. We thought it might be possible to do this by prolonged application of sympathomimetic drugs. This paper describes the action of various drugs on the vas deferens in vitro and in vivo, and also a method of application of these drugs to the vas deferens for a period long enough to permit investigation of the effects on fertility.

\section{Materials and Methods}

\section{In-vitro experiments}

Specimens of human vas deferens $(10-35 \mathrm{~mm}$ long) were obtained from patients undergoing elective vasectomy under local anaesthesia. The operations were performed between 16:00 and 18:00 $\mathrm{h}$. The excised tissues were immediately placed in iced Krebs-Henseleit solution and stored at $4^{\circ} \mathrm{C}$ until use the following morning.

\footnotetext{
* Reprint requests to Dr R. M. Wadsworth.

† Present address: Department of Zoology, Colombo Campus, University of Sri Lanka, Colombo 3, Sri Lanka.
} 
The tissues were suspended in $7.5 \mathrm{ml}$ baths under a resting tension $1.0 \mathrm{~g}$ and contractions were isometrically recorded. The physiological salt solution used for transportation, storage and during investigation had the following composition (mM): $\mathrm{Na}^{+}, 143 ; \mathrm{K}^{+}, 5 \cdot 8 ; \mathrm{Ca}^{++}, 2 \cdot 6 ; \mathrm{Mg}^{++}$, $1 \cdot 2 ; \mathrm{Cl}^{-}, 128 ; \mathrm{H}_{2} \mathrm{PO}_{4}^{-}, 1 \cdot 2 ; \mathrm{HCO}_{3}^{-}, 25 ; \mathrm{SO}_{4}^{-}, 1 \cdot 2$; and glucose, $11 \cdot 1$. It was gassed with $95 \% \mathrm{O}_{2}$ and $5 \% \mathrm{CO}_{2}$ and maintained at $36-38^{\circ} \mathrm{C}$ throughout the experiment.

Drugs were added either cumulatively, increasing the concentration every 8 min, or sequentially, when each dose was washed out once a stable response had been established. Potassium contractions were obtained by the addition of $2 \mathrm{M}-\mathrm{KCl}$ (to give a final potassium concentration of $150 \mathrm{~mm}$ ). The following drugs were used, and concentrations are expressed as $\mu \mathrm{g} / \mathrm{ml}$ of the salt: methoxamine hydrochloride (Burroughs Wellcome, Beckenham, Kent): (-)noradrenaline hydrochloride, tyramine hydrochloride, (-)-norephedrine hydrochloride (Sigma, Poole, Dorset) and phentolamine mesylate (Ciba, Horsham, Sussex).

\section{In-vivo experiments}

The 24 male rats $(250-350 \mathrm{~g})$ and 10 male guinea-pigs $(350-500 \mathrm{~g})$ were anaesthetized with urethane and then placed on a heated operating table in the supine position. A tracheotomy was usually performed. Intravenous injections or infusions were made through a catheter placed in one jugular vein. The carotid pressure was monitored continuously throughout the experimental period by using a pressure transducer (Statham P23V) and a Grass 7B pen recorder.

One vas deferens was exposed and a 5/0 thread was sewn through the connective tissue surrounding the epididymal end. This was connected to an isometric transducer (Grass FTO3C) via a spring with a compliance of $1 \mathrm{~g} / \mathrm{cm}$. The contractions were therefore recorded semiisotonically. The minimum contraction that could be detected with the recorder sensitivity that was used was $0.05 \mathrm{~g}$ (equivalent to $0.5 \mathrm{~mm}$ movement). Some vasa deferentia were electrically stimulated $(50 \mathrm{~Hz}, 40-70 \mathrm{~V}$, pulse width $=0.5 \mathrm{msec})$ through surface electrodes from a Grass SK4 stimulator.

In 2 rats, the skin surrounding the exposed vas deferens was pinned in such a way that a pool could be created in which to immerse the duct. The pool contained $1 \mathrm{ml}$ of a solution of the drug under investigation at a concentration of $1 \mathrm{mg} / \mathrm{ml}$. Throughout the experimental period, the exposed organs of the body were covered with pads of cotton wool soaked in warm saline.

\section{Construction of collars}

An appropriate weight of the powdered sympathomimetic drug was mixed together with a known volume of polysiloxane polymer ("Silastic 382" Medical Grade Elastomer, Dow Corning Corp.) in a mortar for about $5 \mathrm{~min}$. A drop of the hardener (stannous octoate) was then added and further mixing carried out for another 1-2 min. The paste thus formed was immediately transferred into a mould constructed from the inner barrel of a $2 \mathrm{ml}$ disposable polycarbonate syringe. A knitting needle (diameter $2.8 \mathrm{~mm}$ ) was pushed through the centre of the mixture, which was then allowed to set (about $15 \mathrm{~min}$ ). The needle was later withdrawn and the hardened drug-containing Silastic tube removed by crushing the barrel of the syringe. A further layer of the polymer, mixed with its catalyst, was applied to the outer surface of the tube because preliminary experiments had suggested that such an application reduced systemic absorption of drugs. The resulting cylinder was finally cut into 2 or 3 collars, each about $15 \mathrm{~mm}$ long, $8 \mathrm{~mm}$ in diameter with a $2.8 \mathrm{~mm}$ central hole and weighing about $250 \mathrm{mg}$. A longitudinal cut was then made in the wall of the collar to enable its placement around the vas deferens. Control collars consisting entirely of Silastic were prepared in a similar manner.

\section{Insertion of collars around the vas deferens}

After induction of anaesthesia with ether, the prostatic ends of both vasa deferentia of 24 rats were exposed through a $2-3 \mathrm{~cm}$ midline incision by pulling on the epididymal fat pad. Care was taken not to withdraw the testes from the inguinal canals. A collar containing $25 \%$ methoxamine 
hydrochloride (5 rats), 50\% tyramine hydrochloride (6 rats), 75\% tyramine hydrochloride ( 7 rats), $50 \%$ norephedrine hydrochloride (6 rats) or drug-free (5 rats) was then placed around each vas deferens before returning them and the fat pads to their natural positions. The incision was closed and the animal allowed to regain consciousness.

\section{Blood pressure measurements from conscious rats}

The method of inserting a permanent indwelling catheter was similar to that described by Popovič \& Popovič (1960). Six rats were anaesthetized with ether and the right carotid artery was exposed. A polythene catheter was inserted and advanced to the aorta. The outer end of the cannula was taken through the subcutaneous tissue using a trochar and exteriorized at the dorsal surface of the neck and clipped to the skin with two Michel wound clips. The incision was closed and the animals were transferred to individual cages and allowed to regain consciousness. The catheter was flushed through periodically with heparinized $0.9 \%(\mathrm{w} / \mathrm{v}) \mathrm{NaCl}$ solution containing $0.05 \%$ chlorocresol.

The blood pressure was measured continuously for about 30-45 min from the carotid artery, after coupling the polythene tubing to a pressure transducer (Statham P23V).

After measuring the control blood pressure, 3 rats were again anaesthetized with ether and a collar containing $50 \%$ tyramine was inserted around each vas deferens as described above. After the animals had regained consciousness, their blood pressure was monitored at various times for up to 2 days. In a 4 th rat, a control collar was inserted around each vas deferens. Blood pressure was measured for about $30 \mathrm{~min}$ and then a second operation was performed to replace the control collars with $50 \%$ tyramine collars. The blood pressure was then monitored at various times during the next 2 days.

\section{Results}

\section{Human vas deferens}

Of the 44 vasa deferentia investigated, 20 showed spontaneous regular contractions during the equilibration period. The time between mounting the tissue in the bath to the start of spontaneous motility varied from 2 to $15 \mathrm{~min}$. These contractions lasted for $10-15 \mathrm{~min}$ before the muscles became quiescent. The amplitude of these contractions varied from 0.5 to $1.0 \mathrm{~g}$ and the frequency was 2-3 contractions/min. Repeated washings enhanced the disappearance of spontaneous contractions.

Potassium response. Addition of potassium produced a sustained contraction $(0 \cdot 25-2 \cdot 5 \mathrm{~g})$ which was maintained until washing. In a few preparations repeated phasic contractions were superimposed on the sustained contraction.

Noradrenaline, methoxamine, tyramine and norephedrine. All the agonist drugs investigated elicited rhythmic contractions. Four patterns of response could normally be distinguished. Each of these was occasionally observed with any of the drugs at all effective concentrations. However, any one preparation usually exhibited only one or, at the most, two types of activity. (1) An initial tonic contraction (with or without superimposed phasic contractions) followed by phasic contractions (Text-fig. 1a). (2) Single spikes with small contractions preceding or following them (Text-fig. 1b). (3) Phasic contractions in groups of 2 or 3 of roughly equal size (Text-fig. 1c). (4) Phasic contractions in single spikes (Text-fig. 1d). Provided the drug was not washed out, rhythmic contractions continued for the entire duration of the experiment (4-6 h) with no sign of fatigue. This was true for all 4 drugs studied.

The dose-response curve to noradrenaline when the drug was added sequentially is shown in Text-fig. 2(a). A lag of 0.2 to 9 min was observed between addition of each dose and the appearance of the response. With each dose the phasic contractions grew gradually larger, reaching a maximum after 0.5 to $8 \mathrm{~min}$. The contractions could be abolished by repeated washings. 


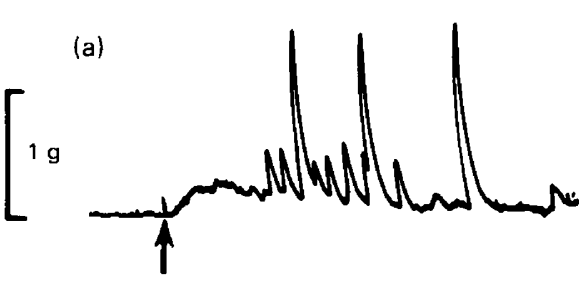

TA

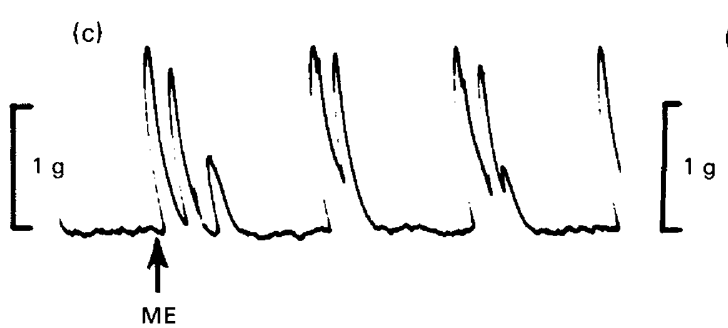

(b)

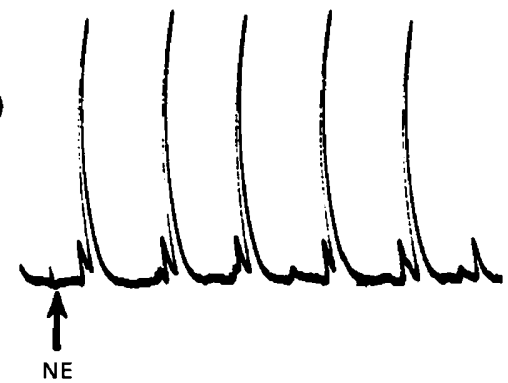

(d)

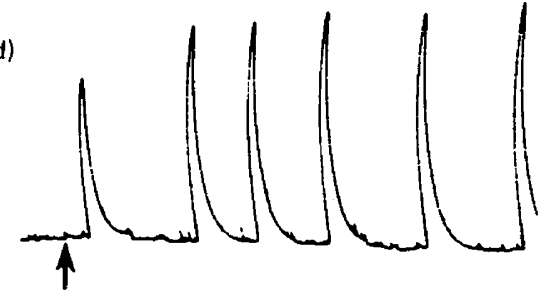

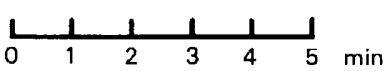

Text-fig. 1. Examples of contractions produced by sympathomimetic drugs in isolated human vasa deferentia to show the 4 types of response ( $a, b, c, d)$ commonly observed. The drugs used, all at $10 \mu \mathrm{g} / \mathrm{ml}$, were tyramine (TA), norephedrine (NE), methoxamine (ME) and noradrenaline (NA), although all of them produced on different occasions responses of each of the types shown. The arrows indicate the addition into the bath of the drugs which were then left in contact with the tissue for the remainder of the period shown.

The cumulative concentration-response curve for methoxamine is depicted in Text-fig. 2(b). The lag period with the first dose was short $(0.5-1.0 \mathrm{~min})$. In contrast to noradrenaline, the maximum response with methoxamine was achieved in less than $0.5 \mathrm{~min}$ after the first contraction. Once repeated phasic contractions had developed, they could not be abolished by repeatedly washing out the bath. The persistence of action of the drug may result from its slow rate of inactivation (Iversen, 1967).

The cumulative dose-response relationship for tyramine ( 8 vasa deferentia) is shown in Textfig. 2(c). Tyramine-induced contractions were similar to those induced by noradrenaline, but tyramine was less potent. A pronounced lag was observed following the first addition to each preparation and was presumably due to the drug's indirect mode of action.

Text-figure 2(d) shows the concentration-response relationship for norephedrine recorded cumulatively ( 3 vasa deferentia). The effect produced by norephedrine was very similar to that brought about by tyramine, suggesting a similar mode of action.

Phentolamine $(2 \mu \mathrm{g} / \mathrm{ml})$ abolished the contractions produced by noradrenaline, methoxamine and tyramine within $2 \mathrm{~min}$.

\section{Effects on vas deferens of anaesthetized rats and guinea-pigs}

No spontaneous activity was observed in any rat or guinea-pig vas deferens under the experimental conditions of this study. The period of observation in different experiments was 3-6 h (Table 1). However, electrical stimulation with surface electrodes produced single contractions ranging from 0.5 to $3.5 \mathrm{~g}$ with $5-35 \mathrm{~mm}$ shortening. Three guinea-pig vasa deferentia gave a double response when stimulated. 


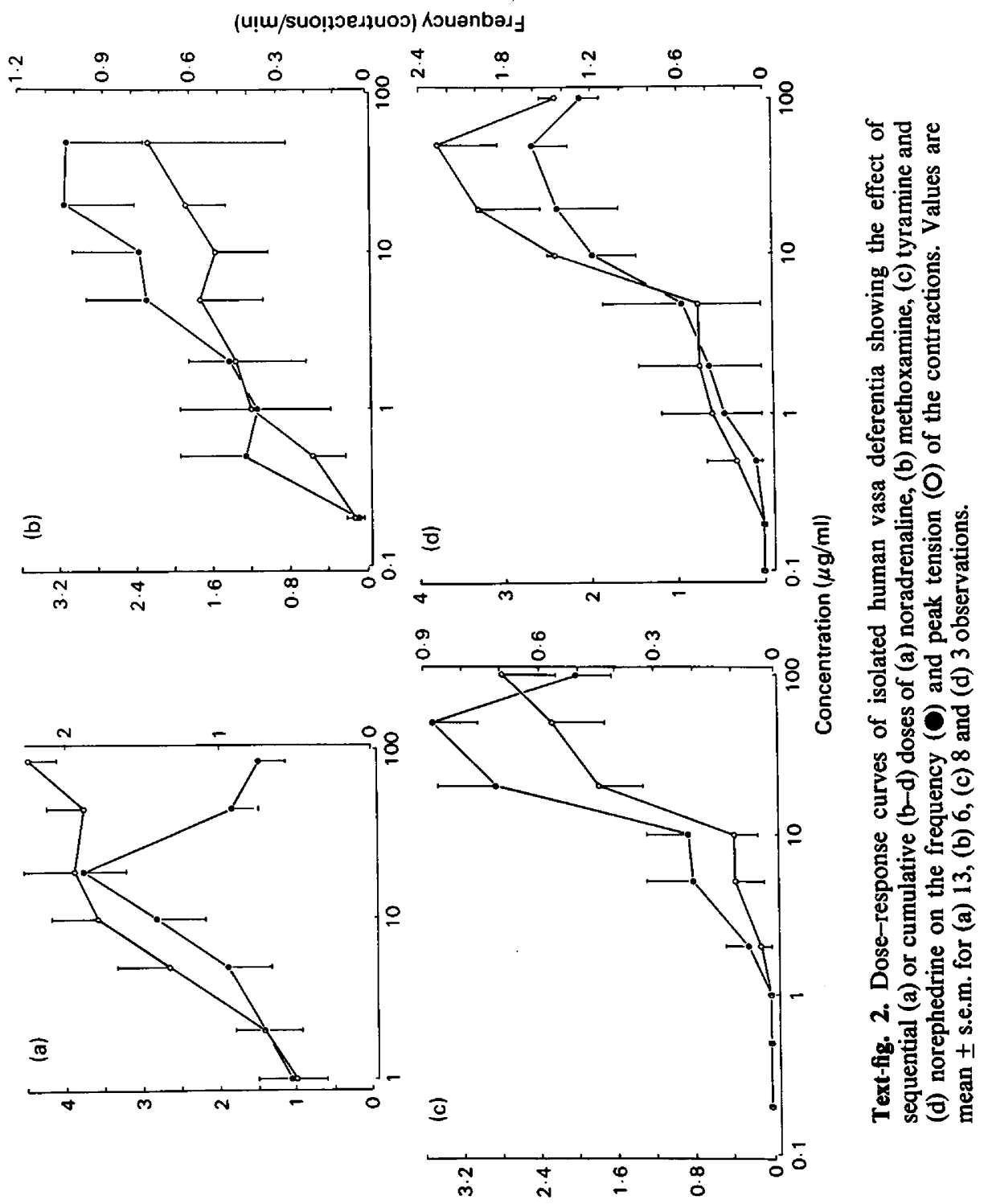

(6) uo!suə 1 


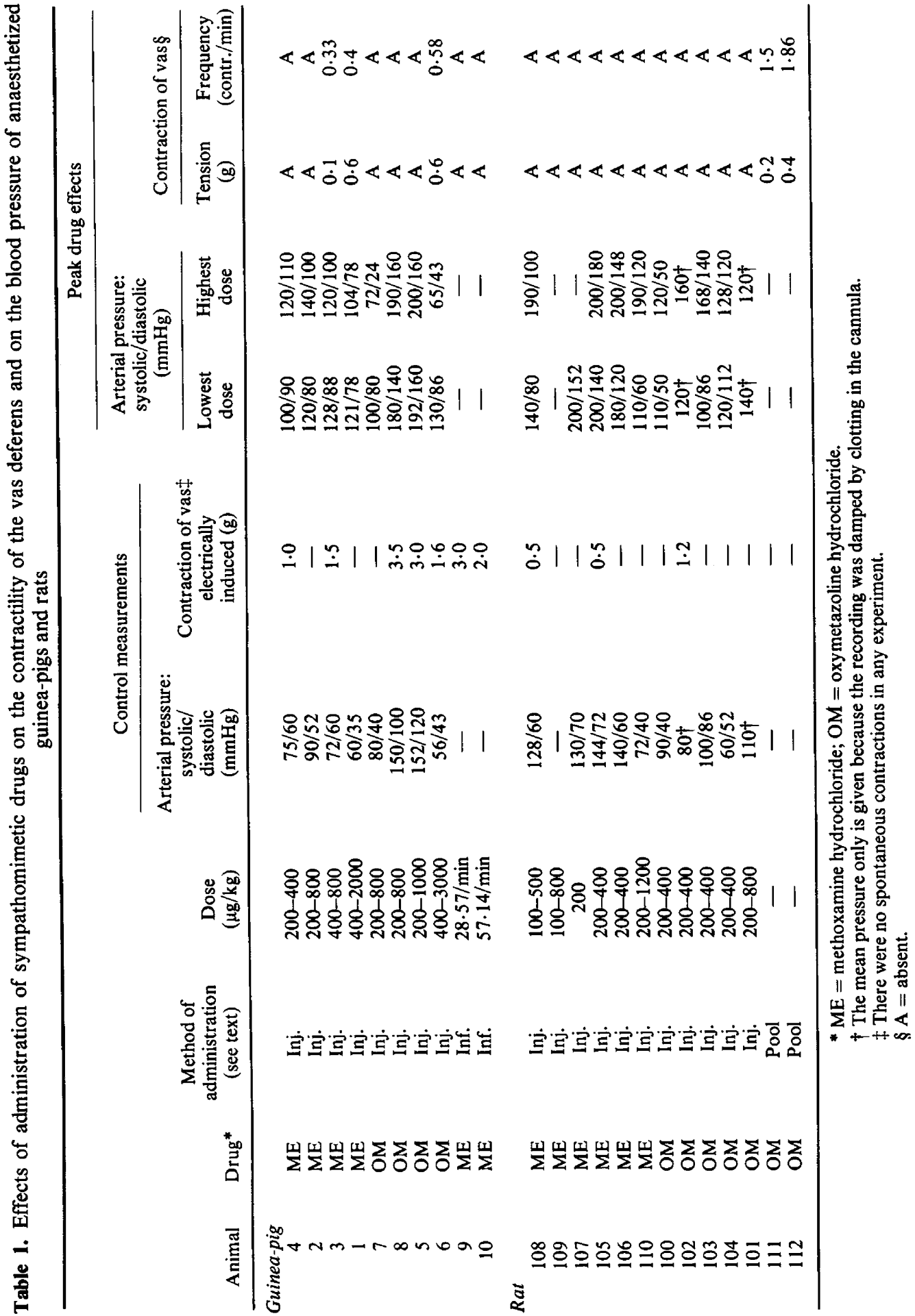


Intravenous administration of drugs. Only 3 out of 10 guinea-pig vasa deferentia responded to intravenous injection of methoxamine hydrochloride or oxymetazoline hydrochloride, and even then very high doses $(1600-3000 \mu \mathrm{g} / \mathrm{kg})$ were required (Table 1). Rhythmic contractions ranging from 0.1 to $0.6 \mathrm{~g}$ were produced. The same drugs in lower doses $(100-800$ $\mu \mathrm{g} / \mathrm{kg}$ ) failed to produce contractions in rat vasa deferentia (11 preparations).

Similarly high doses of methoxamine hydrochloride given as an infusion lasting 20-30 min were also ineffective (Table 1).

Local application of drugs. In 2 experiments, oxymetazoline, administered in the surrounding pool, produced contractions ranging from 0.2 to $0.4 \mathrm{~g}$ at a frequency of $1.5-1.86 / \mathrm{min}$. These responses appeared within $1 \mathrm{~min}$ and lasted about $30-45 \mathrm{~min}$.

Silastic collars containing tyramine or amphetamine (see Table 2, Text-fig. 3) produced contractions in all animals tested (up to 14 days after insertion).

Table 2. Effect of collars containing tyramine or amphetamine on the blood pressure and contractions of the vas deferens of anaesthetized rats at various times after insertion

\begin{tabular}{ccccccc}
\hline & & & & & \multicolumn{2}{c}{ Contraction of vas } \\
\cline { 5 - 7 } Animal & $\begin{array}{c}\text { Type of } \\
\text { collar* }\end{array}$ & $\begin{array}{c}\text { Time after insertion } \\
\text { of collars }\end{array}$ & $\begin{array}{c}\text { Arterial pressure: } \\
\text { systolic/diastolic } \\
(\mathrm{mmHg})\end{array}$ & $\begin{array}{c}\text { Amplitude } \\
(\mathrm{g})\end{array}$ & $\begin{array}{c}\text { Frequency } \\
(\mathrm{min})\end{array}$ \\
\hline 151 & $50 \% \mathrm{AM}$ & $45 \mathrm{~min}$ & $120 / 80$ & $0.05-0.08$ & 0.43 \\
152 & $50 \% \mathrm{AM}$ & $45 \mathrm{~min}$ & $168 / 120$ & $0.24-0.28$ & 0.27 \\
155 & $50 \% \mathrm{TA}$ & $30 \mathrm{~min}$ & $180 / 120$ & $0.08-0.24$ & 0.24 \\
157 & $50 \% \mathrm{TA}$ & $30 \mathrm{~min}$ & $152 / 100$ & $0 \cdot 16-0.4$ & 0.15 \\
154 & $50 \% \mathrm{TA}$ & $45 \mathrm{~min}$ & $100 / 60$ & $0.05-0.08$ & 0.07 \\
153 & $50 \% \mathrm{TA}$ & $45 \mathrm{~min}$ & $160 / 100$ & $0.24-0.48$ & 0.37 \\
158 & $50 \% \mathrm{TA}$ & $45 \mathrm{~min}$ & $156 / 112$ & $0 \cdot 16-0.24$ & 0.19 \\
156 & $50 \% \mathrm{TA}$ & 1 day & - & $0.16-0.24$ & 0.10 \\
159 & $50 \% \mathrm{TA}$ & 14 days & $156 / 116$ & $0.08-0.16$ & 0.20 \\
\hline
\end{tabular}

* $\mathrm{AM}=$ amphetamine hydrochloride: $\mathrm{TA}=$ tyramine hydrochloride.
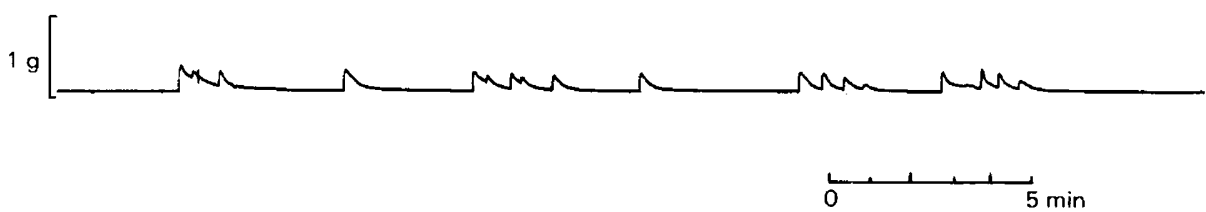

Text-fig. 3. Effect of local application of tyramine on the contractility of the rat vas deferens. A collar containing $50 \%$ tyramine was inserted around each vas deferens. At 14 days following the insertion, the animal was anaesthetized and the contractions of the vas were recorded semiisotonically in situ.

\section{Blood pressure responses}

Injection or infusion of sympathomimetic drugs to anaesthetized rats or guinea-pigs produced a transient rise in blood pressure (Table 1). In some animals, a greater rise was produced by lower doses of the drugs. When tyramine was administered in the form of Silastic collars, the blood pressure appeared to be elevated at the time when contractions of the vas deferens were produced (Table 2). Although arterial pressure appeared to be greater than that in control animals (Table 1), it was not possible to measure the pretreatment pressure in each individual animal before insertion of the collars in the experiments shown in Table 2. A further set of experiments was therefore performed in which catheters were chronically implanted in the carotid artery of rats. After the insertion of tyramine collars there was a transient rise in blood 
pressure while control collars were without effect. The rise in blood pressure was, however, short-lived (about $1 \mathrm{~h}$ ) and was followed by hypotension (Table 3). The first hour after insertion of the collars was also the period when other effects indicative of systemic absorption of the drugs (bulging of the eyes, erection of the fur) were seen.

Table 3. Effect of drug-free or $50 \%$ tyramine (TA) collars on the blood pressure of conscious rats at various times after insertion

\begin{tabular}{|c|c|c|c|c|c|c|c|}
\hline \multirow[b]{2}{*}{ Animal } & \multirow{2}{*}{$\begin{array}{c}\text { Control } \\
\text { arterial } \\
\text { pressure } \\
(\mathrm{mmHg})^{*}\end{array}$} & \multirow[b]{2}{*}{ Collar } & \multicolumn{5}{|c|}{ Arterial pressure after treatment $(\mathrm{mmHg})^{*}$} \\
\hline & & & $\begin{array}{c}15-30 \\
\min \end{array}$ & $1 \mathrm{~h}$ & $3 \mathrm{~h}$ & 1 day & 2 days \\
\hline 150 & 120 & & & & & & \\
\hline 151 & 110 & & & & & & \\
\hline 152 & 135 & $50 \%$ TA & 178 & 145 & 75 & 85 & 85 \\
\hline 153 & 113 & $50 \% \mathrm{TA}$ & 155 & 150 & 110 & 85 & - \\
\hline 154 & 113 & Drug free & 110 & - & - & - & - \\
\hline 154 & 110 & $50 \% \mathrm{TA}$ & 140 & 132 & 120 & 90 & - \\
\hline 155 & 140 & $50 \% \mathrm{TA}$ & 155 & - & 105 & 115 & - \\
\hline
\end{tabular}

* Because the record obtained from chronically implanted catheters was usually damped, the mean of the systolic and diastolic pressures is indicated. The values indicated were the closest available to the times stated.

\section{Discussion}

Ventura, Freund, Davis \& Pannati (1973), McLeod, Reynolds \& Demaree (1973) and Hepperlen, Dalske \& Lacy (1976) reported no spontaneous motility in isolated vasa deferentia removed under local anaesthesia from men. In contrast, about $45 \%$ of the vasa deferentia in the present study exhibited spontaneous contractions for a short period. The development of these spontaneous contractions may perhaps be due to changes in the ionic balance as normal cell metabolism is restored, or to liberation of spasmogenic substances as a result of cold storage. The results of Ventura et al. (1973), McLeod et al. (1973) and Hepperlen et al. (1976) might have been caused by (1) differences in the composition of the physiological solutions used, (2) methods of recording the contractions or (3) the age and the health of the patients.

Several workers have demonstrated that rhythmic contractions can be induced with noradrenaline in human vasa deferentia (Martins, Valle \& Porto, 1940; Birmingham, 1968; Ventura et al., 1973; McLeod et al., 1973; Hepperlen et al., 1976; Anton \& McGrath, 1977) or tyramine (Birmingham, 1968). We have confirmed these results, and have also found that these contractions are very persistent, lasting for the entire duration of the experiment if there is no wash-out. Noradrenaline, tyramine, methoxamine and norephedrine are all sympathomimetic amines (Goodman \& Gilman, 1970). Dose-related responses were produced by all 4 drugs. Abolition of these contractions with phentolamine indicates that the effect was mediated via $\alpha$ receptors, since the drug is a selective $\alpha$-adrenoreceptor antagonist at the concentration used (Wohl, Hausler \& Roth, 1967).

In the isolated vas, rhythmic contractions were readily produced with sympathomimetic drugs. In contrast, high doses were required when administered intravenously to anaesthetized animals, and this leads to severe cardiovascular side effects. The poor effectiveness of intravenous administration may have been due to local vasoconstriction since this was observed to occur and would be expected to limit access of the drugs. A more selective effect on the vas deferens was obtained when the drugs were applied locally in surrounding fluid. This method may have been more successful because the drug would not be dependent on the blood supply for access to the smooth muscle. We therefore searched for a slow-release method of local administration. Mixtures of local anaesthetics and Silastic formed into collars were used by 
Robert \& Oester (1970) and Silastic has also been used for sustained-release formulation of prostaglandins (Kimball, Frielink \& Proteus, 1978) and steroids (Prasad, Singh \& Rajalakshmi, 1970).

Silastic collars incorporating tyramine and fitted loosely round the vas deferens produced rhythmic contractions in the vas similar to those seen in vitro. Contractions were not produced by drug-free collars, and thus any irritant effect of the collars themselves can be ruled out. Studies are still in progress to measure the rate of release of tyramine from these Silastic collars, but there appears to be a significant local release for at least 2 weeks since in one animal contractions were recorded 14 days after insertion. A certain amount of the administered dose must also be absorbed systemically, as indicated by the hypertension, bulging of the eyes and erection of the fur. These side effects lasted only about $1 \mathrm{~h}$, perhaps indicating that systemic absorption was limited to loose or superficially located particles of the drug. It is unlikely that the general health of the animals would be impaired by such a short lasting hypertensive action.

In conclusion, these collars satisfy our requirements for a delivery system that supplies sufficient sympathomimetic drug to the vas deferens to cause rhythmic contractions without serious side effects. The effect of the drug lasted long enough to permit mating studies (Ratnasooriya, Gilmore and Wadsworth, 1979).

We are grateful to Sister Leckie and Mr Dean of the Family Planning Clinic, Glasgow, for their co-operation in making available vasectomy specimens and to $\mathrm{Dr}$ B. L. Furman for teaching us his technique of recording blood pressure chronically. Financial support was provided by the Scottish Hospitals Endowments Research Trust. Methoxamine was donated by Burroughs Wellcome, oxymetazoline by Allen \& Hanburys, and phentolamine by Ciba. W.D.R. was supported by an open Scholarship from the Association of Commonwealth Universities.

\section{References}

Anton, P.G. \& McGrath, J.C. (1977) Further evidence for adrenergic transmission in the human vas deferens. J. Physiol., Lond. 273, 45-55.

Birmingham, A.T. (1968) The human isolated vas deferens: its response to electrical stimulation and to drugs. Br. J. Pharmac. 24, 692-693P.

de Kretser, D.M. (1976) Towards a pill for men. Proc. $R$. Soc. $B$ 195, 161-174.

Goodman, L.S. \& Gilman, A. (1970) The Pharmacological Basis of Therapeutics. MacMillan, London.

Hepperlen, T.W., Dalske, H.F. \& Lacy, S.S. (1976) Effects of prostaglandins, nitrofurantoin and Escherichia coli on response of human vas deferens to norepinephrine. Fert. Steril. 27, 275-281.

Iversen, L.L. (1967) The Uptake and Storage of Noradrenaline in Sympathetic Nerves. Cambridge University Press.

Kimball, F.A., Frielink, R.D. \& Proteus, S.E. (1978) Fertility of male rats treated with $15(\mathrm{~S})$-15-methylprostaglandin $F 2_{\alpha}$ methyl ester containing silastic implants. Fert. Steril. 29, 109-111.

Lubell, I. \& Frischer, R. (1976) The current status of male and female sterilization procedures. Proc. $R$. Soc. $B$ 195, 516-546.

Martins, T., Valle, J.R. \& Porto, A. (1940) Pharmacology in vitro of the human vas deferens and epididymis: the question of the endocrine control of the motility of the male accessory genitals. $J$. Urol. 44, 682-698.
McLeod, D.G., Reynolds, D.G. \& Demaree, G.L. (1973) Some pharmacological characteristics of the human vas deferens. Invest. Urol. 10, 338-341.

Patanelli, D.J. (1975) Suppression of fertility in the male. In Handbook of Physiology, section 7, 5, pp. 245258. Eds D. W. Hamilton \& R. O. Greep. Williams \& Wilkins, Baltimore.

Popovič, V. \& Popovič, P. (1960) Permanent cannulation of aorta and vena cava in rats and ground squirrels. J. appl. Physiol. 15, 727-728.

Prasad, M.R.N., Singh, S.P. \& Rajalakshmi, M. (1970) Fertility control in male rats by continuous release of microquantities of cyproterone acetate from subcutaneous silastic capsules. Contraception 2, 165-178.

Ratnasooriya, W.D., Gilmore, D.P. \& Wadsworth, R.M. (1979) An antifertility effect of sympathomimetic drugs on male rats when applied locally to the vas deferens. J. Reprod. Fert. 56, 643-651.

Robert, E.D. \& Oester, Y.T. (1970) Absence of supersensitivity to acetylcholine in innervated muscle subjected to a prolonged pharmacologic block. $J$. Pharmac. exp. Ther. 174, 133-140.

Ventura, W.P., Freund, M., Davis, J. \& Pannati, C. (1973) Influence of norepinephrine on the motility of the human vas deferens: a new hypothesis of sperm transport by the vas deferens. Fert. Steril. 24, 68-72.

Wohl, A.J., Hausler, L.M. \& Roth, F.E. (1967) Studies on the mechanism of antihypertensive action of diazoxide: in vitro vascular pharmaco-dynamics. $J$. Pharmac. exp. Ther. 158, 531-539. 